\title{
BURGERLIJKE ONGEHOORZAAMHEID EN POLITIEKE VERANTWOORDELIJKHEID
}

Prof. J. Douma.

\section{Definitie}

Laat ik beginnen met de definitie die ik van burgerlijke ongehoorzaamheid in mijn boek Politieke Verantwoordelijkheid reeds gegeven heb: Onder burgerlijke ongehoorzaamheid versta ik dát demonstratieve optreden dat bewust de wet schendt om op dwingende (zij het geweldloos bedoelde) - manier verandering in een wet of maatregel van de overheid tot stand te brengen. Deze definitie stemt ongeveer overeen met wat vrij algemeen onder burgerlijke ongehoorzaamheid verstaan wordt.

Graag wil ik een paar onderdelen uit deze definitie toelichten. Burgerlijke ongehoorzaamheid is een demonstratief optreden. Men overtreedt in burgerlijke ongehoorzaamheid de wet niet in het ge. heim, zoals b.v. bij ontduiking van belasting. Wel kan de weigering om belasting te betalen burgerlijke ongehoorzaamheid zijn. Zo wilde Thoreau (1817-1862) geen 'poll tax' (een soort stemrecht-belasting) betalen, omdat hij tegen de slavernij en de oorlog met Mexico was, waarvan hij vond dat ze beide immoreel en in strijd met de amerikaanse grondwet waren. En vandaag zijn er in Nederland mensen die demonstratief 572 gulden minder aan helasting willen betalen uit protest tegen het plaatsen van 572 kernraketten die door de NAVO op het gebied van de Sovjet-Unie worden gericht. Juist vanwege het demonstratiewe karakter van dergelijke belastingontduikingen, is die ontduiking een vorm van burgerlijke ongehoorzaamheid.

Burgerlijke ongehoorzaamheid wordt verder gekenmerkt door de dwingende manier waarop men een verandering in een wet of maatregel van de overheid tot stand wil brengen. Het gaat dus niet over rustige protestmarsen, waarvan de overheid via de televisie en pers kennis kan nemen, maar over acties die voor de overheid hinderlijk moeten zijn. Men organiseert sit-ins, sleep-ins en kneel-ins, men boycot winkeliers en men ontwricht het verkeer. Men demon. streert zonder toestemming, het protest gaat over in een voor de overheid hinderlijke actie.

In mijn definitie staat verder vermeld dat burgerlijke ongehoorzaamheid streeft naar verandering van een wet of maatregel van de overheid, maar dan op een geweldloos bedoelde manier. Opzettelijk spreek ik over geweldloos bedoeld. Want in de praktijk loopt het dikwijls anders. Er wordt wèl geweld gebruikt. Wie een weg blokkeert, kan verwachten dat geweld niet uitblijft. Bovendien kunnen de gevolgen van een geweldloze actie even hard zijn als van een gewelddadige actie. Een geweldloze blokkade van winkeliers, die hun klandizie verliezen omdat men systematisch weigert nog langer bij hen te kopen, is funester dan wanneer zij alleen maar een pak slaag zouden krijgen. 
Wel heeft het waarde om in de definitie te zeggen dat geweldloosheid bedoeld is, n.l. ter afgrenzing tegen alle bewust gepleegd geweld. Een gebouw bezetten is nog wat anders dan een gebouw opblazen. Daarom valt een actie niet meer onder burgerlijke ongehoorzaamheid wanneer men de bedoeling heeft te vernielen en te doden. Geweldloos bedoeld verzet staat tegenover gewapend verzet. Wil een actie onder burgerlijke ongehoorzaamheid vallen, dan moet er zorgvuldigheid in het omgaan met andermans leven en andermans goederen zijn. Zo niet, dan hebben we met burgerlijk of gewapend verzet te maken, waarin sabotage, gewelddadige acties en guerillamethodes een rol gaan spelen.

\section{Nauwelijks onder dictatoriale regiems}

Het valt niet moeilijk in te zien dat burgerlijke ongehoorzaamheid nauwelijks kansen krijgt onder dictatoriale regiems. In Rusland b.v. kunnen geen kranten verschijnen die kritiek op de regering oefenen. Men kan er geen acties van burgerlijke ongehoorzaamheid organiseren. Protesten van dissidenten bereiken langs niet offisiële weg het Westen en kunnen alleen via radiozenders vanuit het Westen of langs andere, geheime, kanalen de burgers in de Sovjet-Unie bereiken. Verzet is daar dus ondergronds verzet. En het zal juist bovengrond moeten zijn, wil het burgerlijke ongehoorzaamheid he ten.

Ik kan het ook korter zeggen: Burgerlijke ongehoorzaamheid veronderstelt een democratisch besef. Ik zeg met opzet: democratisch besef, en niet: democratische structuur. Er zijn landen (en ik reken daartoe ook Zuid-Afrika) waarin de democratie slechts zeer gedeeltelijk is doorgevoerd, terwijl er toch wel sprake is van een democratisch besef, waarin burgers of onderdanen hun stem kunnen laten horen, zonder dat hun protest onmiddellijk wordit onderdrukt. Een niet-democratische staat is dus nog niet altijd een politie-staat.

\section{Voorbeelden}

Ik geef van burgerlijke ongehoorzaamheid een aantal voorbeelden, die het verschil in democratische sfeer kunnen verduidelijken.

Toen de negers in de Verenigde Staten, voor en tijdens het leven van Martin Luther King, tot acties van burgerlijke ongehoorzaamheid overgingen. streefden zij ernaar dat de gelijkheid van alle burgers, die constitutioneel was vastgelegd en die ook tot algemeen stemrecht geleid had, in de praktijk zou worden geëffectueerd. Het kan wel op papier staan dat alle mensen gelijk zijn, maar het blijkt telkens weer dat (om met George Orwell te spreken) sommige mensen meer gelijk zijn dan anderen! Negers wilden burgers in volle rechten zijn, maar door allerlei bepalingen werd dat geblokkeerd. Het verwerven van eigendom bleef in hun geval een zeer beperkt recht. Verbraken $z i j$ arbeidscontracten, dan werden ze - anders dan de blanken - in de gevangenis opgesloten. In veel cafés en theaters was voor hen geen plaats. Werden ze in het openbare leven door porticuliere organisaties en personen gediscrimineerd, dan viel dat weer niet met de Civil Rights Act te bestrijden. In 1875 gebruikte 
het Gerechtshof het argument dat negers, die uit publieke gelegenheden werden geweerd, door particuliere personen in hun rechten werden aangetast en dat het Congres van de Verenigde Staten dús niet bevoegd was daartegen op te treden. Snelle veranderingen werden bovendien altijd afgewezen met het argument dat daardoor sociale onrust zou ontstaan.

Ik noemde het jaar 1875. De strijd zou voortduren tot ver in deze eeuw. Pas in 1948 werd een einde gemaakt aan de apartheid in de krijgsmacht. Maar apartheid in het onderwijs bleef bestaan, en dan niet alleen op particuliere, maar ook op staatsscholen. Politieke gelijkheid is een mooie term, maar zij wordt als huichelachtig ervaren wanneer men in het openbare leven niet kan gaan, staan of zitten waar men wil. Om daartegen te protesteren weigerde Rosa Sparks haar zitplaats af te staan in een bus aan een blanke man. De Montgomery Bus Boycott werd het begin van een lange reeks activiteiten die als burgerlijke ongehoorzaamheid over heel de wereld bekendheid kregen, vooral ook omdat de naam van Martin Luther King er onverbrekelijk aan verbonden is. Met zijn indringende betogen heeft hij heel wat gewetens wakker geschud.

Dit voorbeeld van amerikaanse burgerlijke ongehoorzaamheid kan ons leren dat deze vorm van ongehoorzaamheid haar plaats vindt in het spanningsveld tussen ideaal en werkelijkheid. Het principe van gelijkheid en gelijke behandeling is het ideaal dat dikwijls ook wel in de grondwet is vastgelegd. Maar de afstand tussen ideaal en werkelijkheid is er altijd, en in veel gevallen is zij zo groot dat spanningen tot ontlading komen.

\section{Ideaal en werkelijkheid}

Het voordeel van de situatie in de Verenigde Staten was, dat er na afschaffing van de slavernij een duidelijke democratische constitutie was gekomen waarin alle onderdanen ook als burgers van gelijke rechten gekwalificeerd waren. Men kon in de strijd voor de burgerrechten teruggrijpen op wat verworven was. En verder was er in de Verenigde Staten een zó sterke democratische gezindheid bij velen dat de spanning tussen ideaal en werkelijkheid moest afnemen.

Dat is in de Verenigde Staten dan ook gebeurd. Is daarmee aan de segregatie tussen blank en swart een einde gekomen? Zeker niet, segregatie zal er waarschijnlik altijd blijven bestaan. Altijd zullen er wel bussen blijven rijden met enkel blanken of enkel zwarten, al was het alleen maar in vakantietijd. Altijd zullen er ook wel kerken blijven waarin enkel blanken of enkel zwarten zitten. Wat zich op een natuurlijke wijze 'eigensoortig' ontwikkelt, moet niemand op kunstmatige wijze vermengen.

De eigen kring en de eigen cultuur, inclusief de eigen beleving van het christelijk geloof, kunnen tot allerlei vormen van ethisch acceptabele apartheid leiden. Maar er is een principieel verschil tussen de situatie waarin ik de deuren van een bus of van een kerk binnen wil gaan en ook mag gaan, juist omdat die deuren naar de straatkant openstaan, en de situatie waarin dat op grond van mijn 
huidskleur niet zou kunnen. Er is veel natuurlijke apartheid die de overheid niet moet bestrijden; er is ook veel schrijnende apartheid die de overheid zelfs met de beste wetten niet kán bestrijden. Maar waar het over gelijke burgers in een en hetzelfde openbare leven gaat, is de overheid geroepen gelijkheid te effectueren, zodat er in het politieke en sociale leven geen tweederangs partners zijn. In de ontwikkeling naar deze gelijkheid heeft de burgerlijke ongehoorzaamheid van Martin Luther King en de zijnen stellig een grote rol gespeeld.

\section{Gandhi in India}

Het volgende voorbeeld brengt ons in India, voordat het in 1947 zelfstandig werd. Daar heeft Gandhi het middel van de burgerlijke ongehoorzaamheid gebruikt om de zelfstandigheid van zijn land tegenover het Britse bewind af te dwingen. Britse goederen en Britse scholen werden geboycot. In 1930 organiseerde Gandhi de zgn. 'zoutmars' naar zee, met de bedoeling zout uit de zee te winnen en daarmee het Britse zoutmonopolie te doorbreken. Gandhi wordt altijd als voorbeeld naar voren gehaald om aan te geven wat burgerlijke onge hoorzaamheid, die geweldloosheid als kenmerk draagt, tot stand kan brengen. Hier moeten echter twee kanttekeningen worden geplaatst.

Ten eerste beoogde Gandhi geweldloosheid. maar bereikte hij dat meerdere malen niet. Men kan de beste bedoelingen hebben, maar het is naief om die bedoelingen te veronderstellen bij allen de aan een actie van burgerlijke ongehoorzaamheid meedoen. Juist omdat het een actie van burgerlijke ongehoorzaamheid is, is de scheidingswand tussen geweldloosheid en geweld dikwijls uiterst dun. Wie het verkeer ontwricht, moet er zich niet over verbazen dat daardoor de emoties oplopen, zodat stenen uit de straat gehaald, winkelruiten ingegooid en auto's in brand gestoken worden. Mensen die burgerlijke ongehoorzaamheid plegen zijn geen duivels, maar ook geen engelen. Er zijn weinig mensen die geweldloos beginnen en dan, eenmaal in de strijd gewikkeld, ook helemaal geweldloos eindigen.

In de tweede plaats: Gandhi bereikte met zijn geweldloos bedoelde en soms ook geweldloos verlopende acties — ik denk aan zijn eigen hongerstakingen - tenslotte zeer veel, maar dan niet omdat geweldloosheid altijd een effectief middel in de politiek is. Het mag vreemd klinken wat ik nu zeg, maar ik meen dat te kunnen verdedigen: Gandhi bereikte met zijn burgerlijke ongehoorzaamheid een bepaald resultaat omdat hij met Britten te maken hadden die wisten wat democratie en democratische vrijheid was, Gandhi kon zich niet - zoals de negers in Amerika - beroepen op een democratische constitutie, want die was er niet. Zijn vijand was het imperialistische Engeland, dat aan Voor-Indië géén zelfstandig bestuur wille schenken. Maar ook imperialistische Britten wisten wel wat democratische vrijheid in hun eigen land betekende; zij wisten daarom dat men mensen niet als dieren of als dingen kon behandelen. En daarom gaven zij - hoe minimaal dan ook - een speelruimte voor protest en burgerlijke ongehoorzaamheid. 
Ik ga geen loflied op de Britten zingen. U hebt in Uw geschiedenis ervaren wat Brits imperialisme betekenen kon. Maar met al hun fouten bleven de Britten toch wel afkomstig uit een land dat weet had van wat vrijheid voor de mens is. Je kunt proberen die kennis te verdringen, en helaas lukt dat dikwijls voor kortere of langere tijd, maar je kunt toch die kennis niet uit je hart branden. Zonder het verder toe te lichten, ben ik van overtuiging dat democratie en de daarmee gegeven vrijheid een christelijke achtergrond hebben, al spelen ook niet-religieuze en niet-specifiek christelijke factoren een rol. Volken en personen die vanuit een christelijke traditie de demo cratie aanvaard hebben als een vooruitgang, of voor het verkrijgen ervan zelfs gevochten hebben, kunnen niet blijvend aan anderen onthouden wat zij zelf als een geschenk beschouwen.

Wat ik met het voorafgaande betoogd heb, kan ik kort ook zo zeggen: Gandhi's geweldloos verzet zou politiek gezien machteloos geweest zijn wanneer hij niet in Voor-Indië, maar in het nationalistisch Duitsland of in het communistisch Rusland gewoond had. In dergelijke situaties immers is het democratisch besef totaal verstikt, ook al neemt met het woord 'democratie' nog in de mond. Onder dictatuur krijgt burgerlijke ongehoorzaamheid geen kans.

\section{Zuid-Afrika als delicaat voorbeeld}

Ik kom bij het derde, en ook het meest delicate voorbeeld: ZuidAfrika. De moeilijkheden in de Verenigde Staten, waarover we hierboven spraken, staan in Zuid-Afrika in veelvoud voor ons. Vormen de niet-blanken in de Verenigde Staten een minderheid, hier in Uw land zijn ze een zeer grote meerderheid binnen de totale bevolking. Bovendien is de verscheidenheid onder de niet blanke bevolking van die aard, dat men rustig van Zuid-Afrika mag spreken als een micro-kosmos, een wereld in het klein, waarin grote verschillen in historische achtergrond en culturele ontwikkeling elke regering voor geweldige problemen plaatsen.

Wie in Europa woont en weet hoe de godsdienst in Noord-Ierland en de taal in België reeds volken kan uiteenscheuren, waarbinnen toch van een homogeen cultureel niveau en van gelijke democratische rechten sprake is, wordt voorzichtig in zijn oordeel wanneer hij aan de omvang van de moeiten in Zuid-Afrika denkt. En wie in het one man one vote het geneesmiddel tegen apartheid denkt te vinden, doet er verstandig aan in Afrika zelf rond te kijken, te beginnen in Zimbabwe - een land bevrijd van apartheid, maar steeds meer in boeien geslagen door een dictatuur die oude stamoorlogen doet oplaaien.

Dat men in Zuid-Afrika een andere weg wilde gaan is zeer begrijpelijk. En dat het woord apartheid een sleutelwoord werd, behoeft evenmin te verbazen. Onder apartheid kan immers de eigensoortige ontwikkeling van alle hier samenlevende volken verstaan worden. Niet het sleutelwoord apartheid, maar de vulling ervan kan alleen beslissen of het op zichzelf juiste streven naar eigensoortige ontwikkeling ook op een moreel verantwoorde wijze werd gerealiseerd. 
Welnu, het valt niet te ontkennen dat de eigensoortige ontwikkeling een door de blanke bevolking opgelegde ontwikkeling werd. $\mathrm{Zij}$ besliste over de andere groepen zonder afhankelijk te zijn van de instemming van die andere groepen. Reeds dat maakt een 'eigensoortige' ontwikkeling uiterst dubieus. Want de ontwikkeling van volken kan geen mechanische, van buiten af opgelegde zaak zijn, als zij de naam van ontwikkeling wil dragen.

Neem de bevolkingsgroep van de Kleurlingen. Van origine zijn ze verbonden aan de blanken en willen ze leven als de blanken, zeker wanneer er onder hen van enige hogere ontwikkeling sprake is. De Kaapse kleurlingen bezaten reeds lange tijd politieke invloed via het stemrecht, samen met de blanken. Maar deze eigensoortige ontwikkeling naar verdere integratie met de blanke bevolking binnen het openbare leven, werd afgesneden door het apartheidsbeleid. De wijze waarop dat gebeurde, heeft veel aandacht getrokken. Toen de vereiste tweederde meerderheid niet gevonden werd in de Volksraad en de Senaat om aan het stemrecht van kleurlingen een eind te maken, werd het ledental van de Senaat uitgebreid om tot die tweederde meerderheid te komen.

Neem ook de miljoenen zwarten van wie verklaard werd dat zij in thuislanden horen, waaraan echter zeer velen geen enkele band meer hebben of willen hebben. Geboren en groot geworden in Zuid. Afrika, werden zij via het apartheidsbeleid vreemdelingen in wat zijzelf als hun eigen land beschouwden. Apartheid betekent voor velen van hen zelfs scheiding tot in de gezinnen toe. Vrouw en kinderen leven in een thuisland, terwijl hun man en vader als trekarbeider op verre afstand zijn werk en zijn leven heeft.

Er is al veel veranderd sinds het apartheidsbeleid met kracht ter hand werd genomen. Er zijn concessies gedaan, soms van die aard dat het lijkt alsof zelfs het uitgangspunt van dit beleid is aangetast. Ik denk aan de verandering van opvattingen over het verbod op gemengde huwelijken en op geslachtsverkeer tussen blank en niet-blank. Maar al zal er, met name door de afschaffing van veel zgn. 'kleine apartheid', klein leed verzacht worden, het grote leed is gebleven, verdiept en uitgegroeid tot verbittering en geweld. Deze verbittering heeft duidelijk gemaakt hoe mensen zich vernederd voelen door bepalingen die, precies als in de Verenigde Staten, meer gericht waren op de eigensoortige (en dan ook eigenaardige!) ontwikkeling van de blanken dan van de niet-blanken.

Ongetwijfeld is er door de blanken veel gedaan voor de nietblanken; maar dat neemt niet weg dat de blanken nog meer voor zichzelf deden. Wie op de herverdeling van de grond let, ziet dat er voor de blanken veel en dat er voor de thuislanden weinig grond is, terwijl de grond voor de thuislanden ook nog zeer verbrokkeld is. Blanken kunnen zich door hun land vrijer bewegen dan de nietblanken. Zij zullen het gevoel niet kennen van de werkloze die naar z'n thuisland gezonden kan worden of van hen die soms al sinds generaties op een zwarte plek in blank gebied wonen en daar vroeg of laat, soms na veel juridische processen, vandaan moeten. Blanken offeren veel voor het onderwijs van de niet-blanken, maar wat zij 
voor hun eigen onderwijs doen, overtreft verre dat wat zij voor de anderen doen.

Ik hoop dat $U$ mij het niet kwalijk neemt dat ik iets uitvoeriger over de situatie in Uw land spreek. Wanneer ik de feiten onjuist heb weergegeven, dan reken ik op Uw correctie. Maar áls deze feiten juist zijn, dan is het te begrijpen dat de situatie in dit land explosief is en het nog steeds meer zal worden. Kleine concessies zullen deze ontwikkeling niet keren.

Elk beleid dat aan miljoenen mensen hun eigensoortige ontwikkeling wil opleggen, zonder dat het voor die mensen ook een zelfstandige en vrije ontwikkeling kan heten, is ten dode opgeschreven. Men kan het een stap in de goede richting vinden dat Zuid-Afrika thans het eerste multiraciale parlement en dito regering heeft. na de invoering van het driekamerig stelsel, bestaande uit blanken, kleurlingen en Aziaten. Maar zolang aan de zwarte bevolkingsgroep, die numeriek de sterkste is. en waarvan waarlijk niet alleen de marxistische woordvoerders hebben betoogd dat zij als burgers en niet als vreemdelingen binnen de Republiek van Zuid-Afrika willen wor. den erkend - zolang aan deze bevolkingsgroep slechts gedecentraliseerde bevoegdheden en geen stem in de nationale politiek gegeven wordt, zullen de spanningen blijven oplopen en zal ook het middel van de burgerlijke ongehoorzaamheid worden aangegrepen om veranderingen af te dwingen.

\section{Zuid-Afrika is niet Sovjet-Unie}

Want - en nu neem ik de draad van mijn betoog over burgerlijke ongehoorzaamheid weer op - evenals in de situaties die ik hierboven noemde uit de geschiedenis van de Verenigde Staten en van India is er in Zuid Afrika genoeg democratisch besef dat het onmogelijk maakt dictatoriaal te worden of in elk geval te blijven. Wie ZuidAfrika binnenkomt, stapt niet de Sovjet-Unie binnen, al wil een deel van de westelijke pers ons dat doen geloven. $\mathrm{Er}$ is hier een grote mate van vrijheid om te schrijven, te spreken en te organiseren.

Er is hier ook de oprechte bedoeling om via het onderwijs allen die laag ontwikkeld zijn meer vorming, en daardoor ook meer zelfstandigheid te geven. Maar juist door al dit goede zal het steeds onmogelijker worden om het huidige apartheidsbeleid te handhaven.

Hoe meer hier in vrijheid nagedacht, geschreven, gesproken, onderricht en vergaderd kan worden, hoe meer het voor de hand zal liggen dat de Republiek van Zuid-Afrika ook eens een zwarte president moet kunnen kiezen. Het one man one vote in het kader van het Westminster-systeem is daarvoor niet vereist. Het zou ook met een vier-kamerig systeem kunnen als daarvoor niet $ð$ la George Orwell geldt: Alle kamers zijn gelijk, maar één kamer (die van de blanken) is meer gelijk dan de andere kamers.

Apartheid in de vorm van verschillende kamers hoeft niet ondemocratisch te zijn. Zij kan inderdaad eigensoortige ontwikkeling respecteren en zeer uiteenlopende bevolkingsgroepen tegen elkaar beschermen. Maar ook dan kan er apartheid in de slechte zin van het woord zijn als de stem van de blanken op nationaal niveau de be- 
slissende stem moet blijven. Tot zolang is het begijpelijk dat er protest, ook in de vorm van burgerlijke ongehoorzaamheid, is en dat ze steeds sterker zal worden naarmate de tijd verstrijkt.

Politieke verantwoordelijkheid

Over onze politieke verantwoordelijkheid in verband met burgerlijke ongehoorzaamheid zou ik graag kort het volgende willen zeggen: Als christen belijd ik dat men tegenover z'n overheid soms ongehoorzaam moet zijn. Men moet God meer gehoorzaam zijn dan de mensen (Hand. 5, 29). Men moet ook het leven van zijn naaste liefhebben boven gehoorzaamheid aan een tyrannieke overheid. Vroedvrouwen die God vreesden, hebben Israëlietische kinderen niet gedood, ondanks het bevel van de Farao (Ex. 1, 17). Daniël bleef driemaal per dag op z'n knieën God bidden en loven, precies zoals hij dat deed vóórdat hem dit verboden werd op koninklijk bevel (Dan. 1,11 ). Paulus bracht het evangelie in Thessalonica ook al zeiden z'n tegenstanders dat hij in strijd met de geboden van de keizer han delde (Hand. 17, 6vv).

Toch zijn er veel zaken waarin de gehoorzaamheid tegenover God niet op het spel staat, zelfs al is er sprake van groot onrecht dat de ene mens tegenover de andere, of ook een overheid tegenover haar onderdanen pleegt. In die gevallen moet ieder protesteren op een legitieme wijze en geen middelen gebruiken die tot ongehoorzaamheid jegens de overheid leiden, met of zonder geweld. De christen moet weten wat onrecht lijden is, hij moet geen onrecht doen.

Daarom wijs ik burgerlijke ongehoorzaamheid als middel in de strijd tegen onrecht af. Ik deed dat in mijn boek Politieke verantwoordelijkheid en ik zie geen reden waarom ik het in Zuid-Afrika anders moet zeggen, ook al wil ik duidelijk stellen dat burgerlijke ongehoorzaamheid én in de Verenigde Staten én in Voor Indië én in Zuid-Afrika zeer begrijpelijk was en is. Maar alles wat begrijpelijk is, is daarom nog niet goed te keuren.

Burgerlijke ongehoorzaamheid is een demonstratief optreden dat op dwingende wijze een verandering in het overheidsbeleid wil aanbrengen. Het wil op papier geweldloos zijn, maar op onze televisie kunnen we zien dat het ook in Zuid-Afrika niet geweldloos blijft. Ik kan ook niet verzwijgen dat de huidige burgerlijke ongehoor zaamheid in Zuid-Afrika, voorzover geleid door theologen, sterk beinvloed is door de theologie van de bevrijding en van de revolutie, waartegen ik uit de grond van mijn hart nee zeg.

Burgerlijke ongehoorzaamheid geen instrument voor gerechtigheid

Maar er is niet alleen een politieke verantwoordelijkheid van de onderdanen in verband met het fenomeen van de burgerlijke ongehoorzaamheid, want uiteraard zal ook de overheid hier haar taak hebben. Zij heeft de orde te handhaven en overtreding van de wet niet straffeloos te dulden.

Maar ik zou mij wel heel ellendig voelen wanneer ik, gelet op alles wat ik hierboven gezegd heb, met deze 'law and order' opmerking mijn betoog moest afsluiten. Want het evangelie van Jezus 
Christus dat niemand vrijmoedigheid geeft aan burgerlijke ongehoorzaamheid mee te doen, zegt ook dat wij dikwijls wel de splinter in het oog van de ander en niet de balk in eigen oog zien. Wanneer Jezus weigert een aanklacht in te dienen tegenover de overspelige vrouw, die op heterdaad betrapt werd en door schriftgeleerden en farizeeën bij onze Heiland gebracht werd, keurt Hij haar houding niet goed. "Ga heen, zondig van nu af niet meer", luiden zijn woorden aan haar adres.

Maar Hij heeft een veel insnijdender boodschap aan farizeeën en schriftgeleerden die op grond van "law and order" de overspelige vrouw gevonnist willen hebben (Joh. 8, 1vv).

Burgerlijke ongehoorzaamheid is geen goed instrument in de strijd voor gerechtigheid. Maar de vraag die elke overheid zich dan lient te stellen is wel: Waar is hier de splinter en waar is hier de balk? Het is ongeloofwaardig wanneer elke uitbarsting van geweld op rekening van communistische agitatie gezet wordt. Duizenden in het buitenland die Uw land een goed hart toedragen en van het communisme een afkeer hebben, weigeren dit te geloven, omdat zij vinden dat het verzet tegen het apartheidsbeleid wel versterkt, maar niet veroorzaakt is door communistische agitatie. De wortel van de problemen én de oplossing ervan moet niemand in Moskau, maar in Pretoria zoeken.

\section{Vriend van Zuid-Afrika}

Ik besef dat ik als gast uit het buitenland vrijmoedig over burgerlijke ongehoorzaamheid en apartheidspolitiek gesproken heb. Het kan nóg vrijmoediger gezegd worden dan ik het reed, ook zonder dat men dan van vriend in vijand van Zuid Afrika verandert. Daarom wil ik iemand citeren die in Zuid-Afrika zelf op een verantwoordelijke post is geplaatst, die met de regering van Uw land wil samenwerken voor een bepaalde vorm van apartheid, die geweld afwijst, maar die dan toch nog wel het volgende durft zeggen. De woorden zijn van de heer Lucas Mangope, president van het thuisland Bophuthatswana, en ze werden gesproken op een Congres van de Afrikaan se Calvinistische Beweging in 1977:

"U Afrikaners bent het juist die mij keer op keer tot aan de rand van de wanhoop brengt. En wanneer het mocht gebeuren dat ik en mijn zwarte geestverwanten over de rand worden gestoten, dan moet $U$ daarvoor niet de Engelstalige pers de schuld geven, noch de druk vanuit het buitenland, noch de opstokers en de anarchisten binnen en buiten onze grenzen. Nee, dan draagt U daar de volle verantwoordelijkheid voor. Door Uw besluiteloosheid, door Uw lege beloften die altijd weer uitlopen op uitstel en afstel, door Uw traagheid om het vergevorderde uur te onderkennen, door Uw lafhartige vrees om de achterblijvers in Uw eigen gelederen het hoofd te bieden. Daarbij gaat het om een vrees, die voor $U$ en voor ons noodlottig kan zijn, want ze is in wezen zelfvernietigend. Ik herhaal het, wanneer de ramp komt, draagt $U$ daarvoor de volle verantwoordelijkheid en wel vanwege Uw kleingeloof".

In het emotionele woord van de heer Mangope proef ik wat ik 
in alle kalmte als samenvatting van mijn gedachten over burgerlijke ongehoorzaamheid en politieke verantwoordelijkheid zou willen formuleren: Wie burgerlijke ongehoorzaamheid afwijst omdat 'law and order' in gevaar zijn, moet zich er niet over verbazen dat 'law and order' hem zullen ontglippen als hij voor het vragen, het smeken en het schreeuwen om recht doof blijft.

\section{VERWYSINGS}

Voor literatuuropgave verwijs ik naar mijn publikatie Politieke verantwoordelijkheld, uitgave Van den Berg, Kampen 1984, 176vv.

Waardevol is het boek van G. Manenschijn, Burgerlijke ongehoorzaamheld, uitgave Ten Have, Baarn 1984, waaraan ik voor deze lezing verschillende gegevens te danken heb. 